\title{
USO DE MEMBRANAS DE UF NA PURIFICAÇÃO DE ENZIMAS DE ORIGEM MICROBIANA
}

\author{
Paula Gonçalves de Aquino Pires ${ }^{1}$; Hebert Felipe Batista Coelho²; Andrea \\ Limoeiro Carvalho ${ }^{3}$ \\ 1. Bolsista PIBIC/CNPq, Graduando em Engenharia de Alimentos, Universidade Estadual de Feira de Santana, \\ e-mail: paulla goncalvez@hotmail.com \\ 2. Graduando em Engenharia de Alimentos, Universidade Estadual de Feira de Santana, \\ e-mail: felipehebert23@hotmail.com \\ 3. Orientador, Departamento de nome, Universidade Estadual de Feira de Santana, e-mail: limoeiro@uefs.br
}

PALAVRAS-CHAVE: enzimas; membranas; ultrafiltração.

\section{INTRODUÇÃO}

O licuri, Syagrus Coronata (Martius) Beccari, pertence à subfamília Arecoideae. Essa é uma espécie predominante nas regiões secas e áridas do bioma Caatinga, com uma área de distribuição que vai desde o norte de Minas Gerais até o sul de Pernambuco, abrangendo ainda os estados de Sergipe e Alagoas (NOBLICK, 1986). Uma maneira extrativista utilizada pelos moradores e cooperativas na região Nordeste do Brasil é a extração do óleo de licuri, que pode ser aplicado na cozinha, indústria de perfumes e de sabão (TREVIZAM et al., 2014). A torta resultante da extração do óleo da amêndoa também é utilizada na ração animal por ser bastante nutritiva, e é justamente esta capacidade nutritiva que possibilita o desenvolvimento de microorganismos de interesse no trabalho desenvolvido (LORENZI, 1992).

A biotecnologia pode ser uma alternativa de valorização das propriedades do licuri, podendo agregar valor comercial mais elevado aos produtos e utilizando menos matéria prima. Para recuperação, purificação e concentração de biocompostos tem-se avaliado o uso da ultrafiltração (UF), que é um processo de bioseparação que surgiu em 1960, e utiliza membranas como barreiras seletivas para efetuar a separação de compostos, o que significa que a separação ocorre devido ao fato das membranas utilizadas serem capazes de restringir a passagem de espécies presentes de um meio para outro (FELLOWS, 2006 apud PEREIRA, 2009). Nessa linha de atuação, o presente trabalho foi desenvolvido com o objetivo de se obter, através de microorganismos do semiárido, enzimas de aplicação em produtos alimentícios, utilizando a UF, de forma a obter um método eficiente de purificação das enzimas produzidas via fermentação semissólida e determinar qual a melhor membrana a ser utilizada nesse processo.

\section{METODOLOGIA}

1. Purificação do caldo fermentado

O extrato enzimático, obtido a partir da fermentação semissólida em torta de licuri, após ser clarificado por centrifugação e filtração à vácuo, foi submetido a um processo de ultrafiltração, à temperatura de $30^{\circ} \mathrm{C}$, na maior pressão de operação tolerável pela membrana utilizada, 2,5 kbar. Para esta etapa do estudo foi utilizado o módulo de ultrafiltração para membrana de conformação plana (Modelo Vivaflow 50, Sartorius), com uma membrana de poliétersulfona com diâmetro de corte de $10 \mathrm{kDa}$. O processo foi realizado com recirculação de extrato até que esse fosse concentrado obedecendo às relações dos fatores de concentração volumétricos de 2, 4, 6 e 8, de acordo com a equação 1 , com retirada de uma alíquota da alimentação, extrato antes do processo, e alíquotas do retido e do permeado ao final do processo. 


$$
F C V=\frac{V_{R}}{V_{0}}
$$

Onde, FCV é o Fator de Concentração Volumétrico, $V_{R}$ é o volume de retido e $V_{0}$ é o volume inicial.

\section{Determinação das concentrações das enzimas}

Na determinação da produção de lipase, uma mistura contendo palmitato de pnitrofenila em isopropanol, surfactante e goma arábica em solução tampão fosfato foi aquecida até alcançar estabilidade e então adicionada de extrato da enzima. O preparo do controle foi feito usando a mistura citada e adicionando tampão fosfato. A leitura da absorbância foi feita em espectrofotômetro em 410 nm (BONINE, 2001).

Na avaliação da produção de pectinase foi preparada uma solução inicial de pectina de alta metoxilação em tampão acetato e enzima (meio indutor incubado). Desta solução foram preparadas as soluções de amostra e controle, que foram lidas em espectrofotômetro em 540 nm (UMSZA-GUEZ, 2009).

\section{RESULTADOS}

Para um melhor entendimento do processo, também foi acompanhada a variação da massa de permeado, para que fosse possível estabelecer se houve alteração na permeabilidade à água e se esta interferiu no fluxo do processo. Esta avaliação foi feita em termos da recuperação do fluxo médio de água destilada através da membrana e seus resultados estão apresentados na Tabela 1.

As variações observadas na Tabela 1 mostram que antes de ser circulado o extrato na membrana ainda nova, esta apresentava uma permeabilidade à água mais elevada, justamente pelo fato da membrana não ter sido utilizada. Observa-se também, que, a medida que a membrana é utilizada ocorre um declínio desse fluxo, ainda que seja conduzida uma etapa de lavagem com solução de hidróxido de sódio 0,5M, na qual a membrana passa por um processo de recuperação.

Tabela 1. Fluxo médio de água destilada.

\begin{tabular}{|c|c|c|c|}
\hline & Fluxo médio $\left(\mathbf{k g} / \mathbf{m}^{2} . \mathbf{s}\right)$ & & Fluxo médio $\left(\mathbf{k g} / \mathbf{m}^{\mathbf{2}} . \mathbf{s}\right)$ \\
\hline Membrana nova & $3,28 \mathrm{E}-02$ & $\mathbf{5}^{\mathbf{o}}$ uso & $1,71 \mathrm{E}-02$ \\
\hline $\mathbf{1}^{\mathbf{o}}$ uso & $3,76 \mathrm{E}-02$ & $\mathbf{6}^{\mathbf{o}}$ uso & $2,49 \mathrm{E}-02$ \\
\hline $\mathbf{2}^{\mathbf{o}}$ uso & $3,04 \mathrm{E}-02$ & $\mathbf{7}^{\mathbf{0}}$ uso & $1,48 \mathrm{E}-02$ \\
\hline $\mathbf{3}^{\mathbf{o}}$ uso & $2,18 \mathrm{E}-02$ & $\mathbf{8}^{\mathbf{o}}$ uso & $1,61 \mathrm{E}-02$ \\
\hline $\mathbf{4}^{\mathbf{o}}$ uso & $2,17 \mathrm{E}-02$ & \multicolumn{2}{|c}{} \\
\hline
\end{tabular}

Esse fato se justifica porque, segundo Habert et al., (2006), durante uma separação real em processos movidos pela pressão, o desempenho da membrana pode variar com o tempo, promovendo um decréscimo da permeabilidade com o tempo. Quanto ao fluxo de permeado foram tomadas medidas da massa de permeado ao longo da ultrafiltração. A Figura 1 mostra o fluxo médio de permeado nos diferentes fatores de concentração dos ensaios experimentais. 
Figura 01. Fluxo de permeado ao longo dos ensaios.

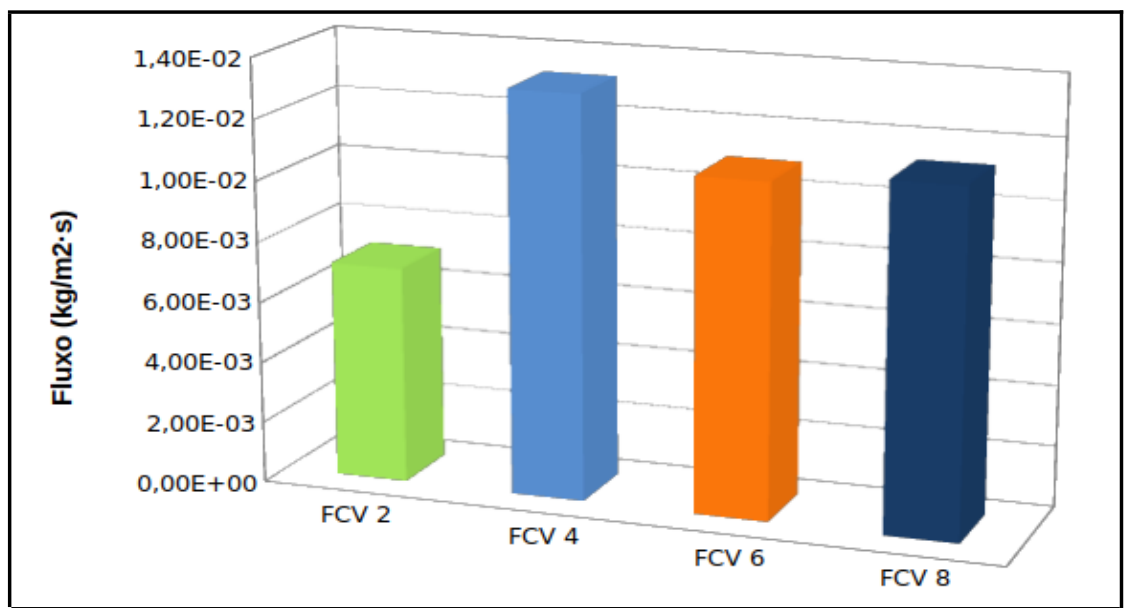

Analisando os resultados do fluxo de permeado para cada fator de concentração volumétrico (FCV) percebe-se que não há variação significativa do fluxo ao longo do procedimento de ultrafiltração. Contudo, ao se comparar o fluxo médio de permeado dos diferentes experimentos, observa-se que o fluxo de permeado aumentou com o FCV, o que indica que o aumento da concentração facilita a separação dos compostos, isso porque o aumento no percentual de sólidos altera o aspecto dos poros da membrana.

A análise de pectinase acusou baixa atividade na alimentação (8,86 U/g substrato seco) e indicou ausência de atividade dessa enzima em todos os fatores de concentração. O fato de existir atividade de pectinase apenas na alimentação, indica que ao longo do processo de ultrafiltração a enzima pode ter sido degradada devido às variações ocorridas durante o processo de ultrafiltração, como o aumento da pressão do sistema. Além da análise de determinação da atividade da pectinase, também foi realizada a análise para determinar a atividade de lipase, cujos resultados estão apresentados na Tabela 2.

Tabela 2. Atividade enzimática da Lipase.

\begin{tabular}{|c|c|c|c|}
\hline & Tempo(min) & $\begin{array}{c}\text { Retido } \\
\text { (U/g de Substrato seco) }\end{array}$ & $\begin{array}{c}\text { Permeado } \\
\text { (U/g de Substrato seco) }\end{array}$ \\
\hline Alimentação & 0 & \multicolumn{2}{|c|}{190,4} \\
\hline FCV 2 & 24 & 0,00 & 138,71 \\
\hline FCV 4 & 40 & 160,28 & 0,00 \\
\hline FCV 6 & 48 & 155,79 & 79,39 \\
\hline FCV 8 & 64 & 151,29 & 9,29 \\
\hline
\end{tabular}

A partir dos dados apresentados na Tabela 2 percebe-se que existia na solução de alimentação do sistema de ultrafiltração uma atividade de lipase mais elevada. Com a continuidade do processo na membrana observa-se que ocorrem variações nessa atividade entre os FCVs. No FCV 2, que foi o primeiro a circular pela membrana, ainda com a permeabilidade inalterada, nota-se atividade da lipase apenas no permeado no final do processo. Para os demais fatores se observa que a atividade no retido é muito maior que no permeado, isso é justificado pelo fato da membrana ter suas características alteradas com o uso. 


\section{CONSIDERAÇÕES FINAIS}

Ao longo dos resultados obtidos verificou-se que, para o processo de ultrafiltração, é necessário maior controle dos parâmetros como temperatura e pressão para que estes não causem interferências significativas sobre as atividades enzimáticas, sobretudo da pectinase. A membrana utilizada mostrou-se adequada ao processo, por não ter provocado alterações de fluxo de permeado ao longo do experimento, e apresentou, também, a possibilidade de recuperação, através da lavagem com solução básica, de modo que parte da permeabilidade seja recuperada. Sua reutilização, entretanto, deve ser melhor investigada devido às diferenças observadas nos resultados dos experimentos subsequentes, pois esse é um fator importante, uma vez que, em aplicações reais, utilizar membranas em purificação de enzimas pode reduzir os custos operacionais, desde que seu uso prolongado seja possível.

\section{REFERÊNCIAS}

BONINE, B.M. Produção de lipase pelo fungo Mycelio phthora sp. F. 2.1.4, caracterização e imobilização da solução enzimática bruta. Dissertação (Mestrado em Microbiologia Industrial, Ambiental e de Alimentos) - Universidade Estadual Paulista. 2011.

FELLOWS,P.J.; Tecnologia do processamento de alimentos: Princípios e Práticas. In: PEREIRA, I.O.; Análise e otimização do processo de ultrafiltração do soro de leite para produção de concentrado proteico. Dissertação (Mestrado em Engenharia de Alimentos) - Programa De Pós-Graduação Em Engenharia De Alimentos. Universidade Estadual do Sudoeste da Bahia, Itapetinga -Ba, 2009.

HABERT, A.C, BORGES, C.P., NOBREGA, R. Processos de separação por membrana. E-Papers , Rio de Janeiro, 2006.

LORENZI, H. Árvores brasileiras: manual de identificação e cultivo de plantas arbóreas nativas do Brasil. Nova Odessa: Ed. Platarum, 1992.

NOBLICK, L.R. 1986. Palmeiras das caatingas da Bahia e as potencialidades econômicas. In: BARBOSA, A.E.A.; et.al. Série de Boas Práticas de Manejo para o Extrativismo Sustentável e Orgânico. MAPA. Brasília, DF. 2012.

UMSZA GUEZ, M.A. Produção de poligalacturonase em fermentação em estado sólido pelo fungo Thermomucor indicae-seudaticae N31 em escala de frascos e biorreator de leito fixo -Tese (Doutorado) - Instituto de Biociências, Letras e Ciências Exatas da Universidade Estadual Paulista “Julio de Mesquita Filho”, Campus de São José do Rio Preto. 2009.

TREVIZAM, C.J., CORREIA, D., DUARTE,V.T. R., Otimização do Processo de Extração do Óleo de Licuri (syagrus coronata). Revista Engenho, v.10, 2014. 